\title{
O PAPEL DA SEQÜÊNCIA TEMPORAL NA COESÃO DO TEXTO
}

\author{
Ana Maria de Mattos Guimarães
}

RESUMO: Dans le cadre de la Linguistique du Texte, cet article pretend exploiter un aspect concernant à la cohésion textuelle: la séquence temporelle. En analysant la fonction de l'oppositon temps/aspect dans le discours des enfants brésiliens de 9 à 12 ans, on a l'intention de: (1) examiner les formules temporelles utilisées par les enfants; (2) observer les différences aspectuelles dans le cadre du foreground et du background des récits; (3) vérifier le rôle joué par (1) et (2) dans la cohésion des textes.

PALAVRAS-CHAVE: coesão textual, mecanismo de seqüência temporal, oposições tempo/aspecto, desenvolvimento do texto infantil, narrativas, foreground, background.

A perspectiva de apresentar um trabalho analítico a partir dos pressupostos da Lingüística Textual abre-nos a possibilidade de melhor explorar um aspecto que consideramos concernente à coesão textual, ao qual denominamos de seqüência temporal. Inicialmente cabe-nos, entretanto, afirmar que estamos inserindo nosso trabalho numa fase da Lingüística Textual que Beaugrande (1990, p.11) chama de lingüística da textualidade. Abandonada a pretensa divisão entre sintaxe textual/semântica textual/pragmática textual, o texto passa a ser entendido como uma rede de opções tanto gramaticais (i.e., sintáticas), como semânticas e pragmáticas, que estão disponíveis para serem relacionadas no momento de sua ocorrência em uma interação comunicativa.

A partir dessa compreensão da Lingüística Textual, a orientação seguida em nosso estudo teórico sobre coesão (GUIMARÃES, 1990) foi funcional ou relacional, muito mais que analítica ou segmental. Adotando uma perspectiva sintático-semântica (estendendo-se o conceito semântico para incluir o pragmático), tratamos a coesão como uma propriedade relacional da ocorrência de elementos lingüísticos na superfície textual, elementos esses que se apresentam ligados entre si de modo a assegurar uma relação significativa entre eles e a garantir o sentido do 
texto como um todo. Julgamos ainda que a coesão assim considerada pode ser descrita em termos das ligações formais (semânticas e sintáticas) entre as partes do texto, que caracterizamos como mecanismos coesivos, i.e., como recursos linguiísticos a serviço da coesão. Entre esses mecanismos incluímos a sequiência temporal.

\section{A SEQÜENCIA TEMPORAL COMO MECANISMO COESIVO}

As relações temporais entre eventos e situações nos textos são assinaladas por diferentes recursos lingüísticos, entre os quais se pode distinguir:

a) marcadores de valor temporal, como as flexões verbais, certas conjunções, advérbios e expressões de valor adverbial;

b) marcadores da relação continuidade/pontos isolados, como é o caso do aspecto verbal e de determinadas expressões que retomam partes do texto (e.g. de novo);

c) marcadores da relação antecedente/subseqüente, em que a descrição do estado anterior deve preceder a descrição do estado posterior e que pode ser verificada pelo uso de expressões que assinalam a ordenação dos elementos em um conjunto (como os numerais), com a função de exprimir a ordem pela qual o falante "teve a percepção ou conhecimento de um dado estado de coisas, como em 'Primeiro vi o automóvel, depois o condutor" ou com que "vão apresentados e desenvolvidos os assuntos sobre que um dado texto fala" (MIRA MATEUS, 1983, p.198).

Esta listagem inicial nos dá uma idéia da complexidade do mecanismo abordado. Observe-se que estamos tratando ainda de elementos que marcam a temporalidade tanto de modo dêitico, como puramente textual, como mostram os exemplos:

(1) Hoje está frio.

(2) Ontem Paula saiu com Mário.

(3) No dia seguinte à festa, Paula contou as novidades.

Os dois primeiros exemplos tratam de uma relação direta com o momento da enunciação, o tempo da fala, apresentando indicadores temporais dêiticos. Já o exemplo (3) mostra indicações temporais cujo ponto de referência encontra-se dentro do enunciado, a partir do sintagma nominal a festa, que, por sua vez, relaciona-se ao momento da enunciação pelo uso de um tempo do passado. Nesse caso, o indicador temporal no dia seguinte é não-dêitico.

Correlacionado ao até agora apresentado, para dar conta dos diferentes eventos relatados em um texto, sente-se a necessidade de três noções de tempo para a especificação temporal, noções apresentadas por Reichembach (1947), da seguinte forma: Tempo da Fala, referente ao tempo do ato de fala ou da enunciação; Tempo de Referência, como um ponto estabelecido com relação ao 
tempo da fala; Tempo do Evento, um ponto estabelecido com relação a outros eventos. Isto quer dizer que, em uma sentença como:

(4) Ontem Pedro já tinha entregue todo o relatório,

pode-se assinalar um tempo de referência (ontem), ancorado em um tempo de fala (momento da enunciação) e um tempo do evento, anterior ao tempo de referência (assinalado pelo emprego do mais que perfeito).

Essas noções, concebidas para os limites da sentença, necessitam ser entendidas de forma mais dinâmica, para dar conta do texto, uma vez que, ao longo de um texto, podem ocorrer modificações não apenas no tempo dos eventos, como, a partir deles, no tempo de referência. Veja-se a esse respeito uma possível continuidade para (4):

(5) Hoje ele não veio trabalhar. Resolveu dormir até mais tarde e folgar o resto do dia,

que altera o tempo de referência para hoje, expressão a partir da qual serão interpretados temporalmente os demais eventos do texto. Isto quer dizer que o tempo de referência é a perspectiva temporal dos eventos, que pode, entretanto, ser alterada pela localização temporal da sucessão de eventos, como foi demonstrado pela sequiência dos exemplos (4) e (5).

Em um texto, tanto os indicadores dêiticos como os não dêiticos têm função coesiva, desde que seja assegurada ao ouvinte/leitor a possibilidade de recuperar a indicação temporal, para localizar o momento da ocorrência relatada no texto. Caso isso não seja possível, ocorrerá ruptura da coesão textual.

Por outro lado, tomando-se um tipo específico de texto, como o narrativo, outras condições precisam ser observadas para que não ocorra ruptura de sua coesão. Numa seqüência narrativa, cada evento tende a mover o tempo de referência para frente (tomando-se como parâmetro o tempo de referência do evento narrativo anterior). Dessa forma, as sequiências não podem ser avaliadas diretamente com respeito ao momento da enunciação. Mesmo que o primeiro evento narrado se ancore no momento da enunciação, os eventos subseqüentes estarão diretamente relacionados ao ponto de referência inicial. Nesse sentido, Reinhart (1984) reafirma determinados estudos a respeito de narrativas ficcionais ou literárias sobre a irrelevância do momento da enunciação (ou do Tempo de Fala), uma vez que "o mundo temporal do texto deve ser constituído 'internamente', e ele constrói seu próprio 'presente narrativo' com respeito ao qual todos os eventos são avaliados" (op. cit., p.786).

Todas essas questões até aqui apresentadas mostram a complexidade do mecanismo coesivo que denominamos de seqüência temporal e nos levaram a verificar como a criança desenvolve seu domínio. Partimos da experiência de encontrarmos freqüentemente em redações escolares o uso alternado de tempos verbais que, à primeira vista, poderia ser considerado ruptura de coesão. $\mathrm{O}$ exemplo a seguir foi retirado de uma redação de $3^{\text {a }}$ série, de uma criança de 8;9 anos:

[...] o menino estava vendo o burrinho na chuva o menino ficou olhando o burrinho Dudu.

O nome do menino é Julho e do burrinho Dudu. 
O burrinho estava passando e o menino olhando na janela.

O burrinho está todo molhado e tomou um banho de chuva e ele está resfriado e com uma tosse [...].

Aparentemente, a alternância entre tempos verbais e aspectos verbais diferentes poderia representar uma ruptura da seqüência temporal do texto. Se enfocarmos, porém, o parâmetro que Hopper (1982) considera fundamental para a organização dos eventos no enunciado, o da discrição, nossa análise pode apresentar resultado diverso da hipótese inicial. Para Hopper, os eventos precisam estar limitados dentro do discurso em sua concepção e conclusão, de modo que seus limites respeitem eventos adjacentes. Entre um dado evento e aqueles que o precedem ou seguem não pode ocorrer sobreposição, pois isto acarretaria ambigüidade. Já estados, processos em desenvolvimento e eventos repetitivos não estão limitados dessa forma e não necessitam ser percebidos separadamente (discretamente), pois, por característica, não são tão ordenados e sua sobreposição não ambigüiza a ordem cronológica dos eventos.

Assim, no exemplo anterior, o uso do presente na segunda frase não representa ruptura temporal, pois está apresentando uma característica dos personagens que não precisa ser percebida com discrição, já que faz parte do background (segundo plano) da história. Só quando ocorrer rompimento com esse parâmetro aspectual, causando obscurecimento até da verificação do que é evento e do que é estado ou ação em desenvolvimento, é que será apontada uma ruptura coesiva.

Veja-se também o outro uso do presente na última frase do texto. Nela, o pretérito perfeito age como um mais-que-perfeito em relação ao presente histórico (i.e., este presente refere-se ao tempo passado) apresentado ("o burrinho está/estava todo molhado, e tomou/tinha tomado banho de chuva..."). O que parece romper com a coesão do parágrafo não é o uso do presente em contexto de passado, mas o uso de $e$ com valor causal (= pois). Observe-se que a criança, talvez por não dispor dos recursos lingüísticos de que se valeria um adulto, procurou outros recursos com a mesma função. Isto não pode deixar de ser considerado quando se analisa o mecanismo de sequiência temporal no texto infantil.

Relacionado ao que foi apresentado sobre aspecto, Hopper (1979) propõe a distinção entre as categorias aspectuais:

(a) durativa ou Imperfectiva;

(b) punctual ou Perfectiva,

com base em sua função discursiva: (b) é usada para relatar ou narrar eventos, enquanto que (a) fornece informações em desenvolvimento, no background narrativo.

No discurso narrativo, as orações Perfectivas convergem para a linha principal da história (foreground), apresentadas em ordem sequiencial, cada uma denotando um evento discreto, contigencial ao completamento do evento anterior. Em relação à sua função pragmática, pode-se afirmar que Perfectivo e Imperfectivo relacionam eventos nas suas relações uns com os outros. 
Pode-se ainda destacar casos em que a mudança temporal tem uma finalidade pragmática. Assim, por exemplo, é admissível o uso de um presente, no contexto do passado, no momento da complicação narrativa, se o narrador tem a intenção de tornar próximo do ouvinte/leitor o momento do relato, ou seja, trazê-lo para o momento da enunciação. Como afirma Wolfson (1979), o Presente Histórico marca juntamente com o Passado um traço discursivo, pois a alternância dos dois tempos em narrativas orais serve para "estruturar a experiência sob o ponto de vista do falante e dramatizá-la" (p.216).

Fleischmann (1985) mostra que a função das formas temporais na narrativa não é apenas a de marcar a referência temporal, aprioristicamente assinalada como passado na maior parte das narrativas, mas a marcação de tempo pode ter uma função pragmática na organização do discurso narrativo. Traz exemplos do francês arcaico para apontar a possibilidade de a inserção do presente em uma narrativa do passado ser uma estratégia para o que chama de grounding da narrativa (plano de fundo). Em seu corpus, a troca entre passado e presente ocorreu quando houve uma interrupção na linha temporal para inserção de elemento do background da história.

Essa estratégia seria motivada por condições pragmáticas das narrativas orais, como uma espécie de compensação para as limitações paratáticas. Fleischman conclui pela existência de uma estreita relação entre troca de tempo verbal e parataxe. Afirma ainda que essas características do texto medieval por ela estudado estão presentes nas narrativas orais quotidianas. Mostra que nesses textos existe uma subordinação narrativa, que não é assinalada por uma subordinação lingüística.

Schiffrin (1981), após cuidadoso estudo sobre a variação do tempo na narrativa oral, conclui que a alternância entre Presente Histórico e Passado na complicação narrativa é um indício dramático importante. Verificou também que a tendência de verbos de um tempo aparecerem juntos pode ser vista como uma explicação funcional, no nível discursivo, para a manutenção dos eventos em uma cena ou episódio (embora não possa ser entendida como unificação de atos em único evento), enquanto a troca separaria eventos entre si. Observe-se que a composição infantil apresentada anteriormente vale-se dessa alternância para assinalar a troca de eventos.

Prende-se a estas afirmações a importância da verificação do quesito troca de tempo, quando se trata de analisar produções narrativas orais. Ligado ao que foi posto, pode-se concluir que o rótulo de ruptura temporal, nos casos de inserção de presente em narrativas de passado, só cabe quando não podem ser detectadas condições pragmáticas que a justifiquem. 


\section{ANÁLISE DO MECANISMO DA SEQÜÊNCIA TEMPORAL EM TEXTOS DE CRIANCSAS DE 9 A 12 ANOS}

É preciso salientar que o corpus analisado foi composto por 160 histórias (80 na modalidade oral e 80 na escrita) contadas por 40 crianças, com idades variando de 8;9 a 12;10 anos. Tais crianças foram agrupadas de acordo com a sua faixa etária, e cada grupo contou com dez crianças, meninos e meninas, de níveis sociais diferentes. Os grupos ficaram assim constituídos:

\begin{tabular}{|l|l|l|}
\hline G1 & $8 ; 9$ a $9 ; 8$ anos & $3^{\text {a }}$ série do $1^{\circ}$ grau \\
\hline G2 & $9 ; 9$ a $10 ; 9$ anos & $4^{\text {a }}$ série \\
\hline G3 & $10 ; 7$ a $11 ; 9$ anos & $5^{\text {a }}$ série \\
\hline G4 & $11 ; 1$ a $12 ; 10$ & $6^{a}$ série \\
\hline
\end{tabular}

Foram coletados dois tipos de histórias: narrativas de experiência pessoal e história contada a partir de sequiência de gravuras. As narrativas pessoais (ROMAINE, 1985) correspondem a relatos (R) que ocorrem normalmente na conversação, tendo sido utilizadas inicialmente por Labov e Waletzky (1967), para análise sociolingüística.

Para a coleta do segundo tipo de história, foi utilizada uma tira de história em quadrinhos (HQ), apresentando uma história muda em 4 cenas. As 4 figuras, na sua ordem seqüencial, representavam uma narrativa, cujo momento inicial poderia acontecer com qualquer uma das crianças que resolvesse desenhar num muro. A primeira cena apresentava um personagem (uma menina) desenhando um boneco numa parede. A segunda cena mostrava um segundo personagem, também do sexo feminino, com ar doméstico (vassoura na mão, lenço na cabeça), que surpreendia a menina no ato de desenhar e a repreendia na terceira cena, quando a menina apagava o boneco. Na última cena, o boneco aparecia desenhado de forma diferente do início, cumprimentando (ou melhor, tirando o chapéu) a pessoa que interpelou a menina.

Tendo em vista a limitação de páginas deste artigo, enfocaremos na análise a função das oposições tempo/aspecto no discurso das crianças, deixando de lado as relações temporais por elas estabelecidas e a própria contextualização temporal das narrativas. Nosso objetivo será mostrar (1) que formas temporais são usadas pelas crianças, (2) que diferenças aspectuais podem ser constatadas e (3) que papel desempenham tais formas com relação à coesão textual.

$\mathrm{O}$ fenômeno da alternância entre passado e presente tem sido motivo de numerosos estudos de pesquisadores da estrutura e organização da conversação quotidiana (WOLFSON, 1979, 1982; SCHIFFRIN, 1981; SILVA-CORVALẢN, 1983) e de narrativa ficcional (REINHART, 1984; FLEISHMAN, 1985). Na base de todos esses estudos, embora não sejam totalmente consonantes entre si, está o fato de que os tempos verbais apresentam, além da função básica de localizar eventos com relação ao momento da fala (ou a outro de referência alternativo), uma 
função pragmática na organização do discurso narrativo. Nesse sentido, a troca de tempo verbal funciona como uma estratégia para a montagem de uma narrativa. Para prosseguir nessa linha de argumentação, faremos uso das noções de foreground e background.

Em qualquer narrativa, algumas partes são mais centrais do que outras. Pode-se fazer uma distinção entre essas partes, seguindo o preconizado por Hopper e Thompson:

Aquela parte do discurso que não contribui imediatamente para o objetivo do falante, mas meramente o assiste, amplia ou comenta, é referida como background. Em contraste, aquele material que suporta os pontos principais do discurso é conhecido como foreground. [...] Juntas, as porções de foreground encerram a espinha dorsal formando sua estrutura básica; as orações de background colocam carne no esqueleto, mas são estranhas à sua coerência textual.

(HOPPER \& THOMPSON, 1980, p.280).

Um dos critérios para depreensão do foreground de uma narrativa pode ser tomado de Labov (1972), ao se dizer que foreground de uma narrativa é constituído por uma sequiência de orações temporalmente ordenadas e qualquer mudança na ordenação dessas orações assinala uma mudança na ordem dos eventos representados.

As orações de background, como vimos, não se encontram em uma linha de tempo, i.e., não são ordenadas, podendo ser deslocadas. Por outro lado, as orações de foreground movem para a frente a linha do tempo da história.

As relações de background e foreground são expressas através do relacionamento de distinções semânticas e gramaticais disponíveis na língua para assinalar níveis de relevância da informação. Uma dessas distinções diz respeito às categorias verbais. Em português, emprega-se para o background de uma história o uso contrastivo do imperfeito, do presente, do passado progressivo e do presente progressivo; para o foreground temos três possibilidades: passado próximo (pretérito perfeito), passado remoto (pretérito mais que perfeito) e o presente. Essas categorias verbais não apenas contrastam num eixo temporal (o que é enfatizado pelas gramáticas tradicionais), como também precisam ser considerados os fatores pragmáticos que representam. Em outras palavras, não vale apenas entender a função geral que tais formas representam, mas é preciso que se busquem também suas funções particulares dentro do contexto discursivo. tradicionais:

A função geral dessas formas é assim definida pelas gramáticas

- o presente é usado para focalizar um evento, que pode coexistir com o momento da fala sem consideração a seus limites temporais;

- o presente histórico é usado em narrativas de eventos presentemente passados, como se eles tivessem ocorrendo no momento da fala;

- o pretérito apresenta o início ou término de um evento num tempo anterior ao momento da fala; 
- o imperfeito foca um evento no passado, como durativo, iterativo ou habitual, mas sem referência ao momento de seu início ou término.

Com relação ao aspecto, diz a gramática tradicional que o presente e o imperfeito são imperfectivos e os pretéritos perfeito e mais que perfeito são perfectivos, i.e., apresentam um evento como terminado ou completado. As formas progressivas correspondentes são imperfectivas, pois focalizam um evento quanto à sua duração ou progressão.

Observemos agora se essa função geral cobre o funcionamento das categorias verbais dentro do discurso. Para tal, valer-nos-emos das alternâncias ocorridas entre presente e passado, começando por aquelas que aconteceram no foreground das narrativas. O consenso que percorre nossas gramáticas tradicionais, com base no escrito, a respeito dessa troca, é o de que o uso do presente histórico $(\mathrm{PH})$ é um artifício estilístico para aumentar o efeito dramático de uma história, fazendo com que o ouvinte/leitor sinta-se presente no tempo do evento relatado. Vejamos se esse consenso permanece na análise do oral e do escrito não-literário.

Carolina - G1/E - Era uma vez uma menina que fez um boneco daí chega a mãe dela e ela gostou a menina achou o desenho muito feio e apagou. E daí a menina desenhou um mais bonito e gostou.

$\mathrm{O}$ uso do presente pertence nitidamente ao foreground da história, tendo como tal um aspecto perfectivo, o que implica que não pode ser substituído por um imperfeito. O uso desse presente serviu na narrativa a duas finalidades: comunicar que a orientação da história tinha acabado, ou seja, estava passando do background para o foreground, e mostrar que a ação da chegada da mãe era imprevista. (Isto é confirmado em outro exemplo de Diogo - G2/O, que torna a relação de contrariedade mais explícita, pela presença de de repente: "Uma guria estava pichando uma parede de uma casa de repente a dona da casa abre a porta...")

Contrariando a visão tradicional da função do presente histórico na narrativa, Wolfson (1979) demonstroü que o uso de PH na conversação não tem um significado por si mesmo, mas é a alternância entre PH e passado que constitui um traço expressivo. Isso parece conferir com o uso que descrevemos anteriormente. A troca para $\mathrm{PH}$ colocada dentro do foreground da narrativa cria o efeito do imediato e faz a narrativa mais vívida e dramática. O maior suporte para esta conclusão (semelhante a de Silva-Corvalán, para o espanhol) é a co-ocorrência de PH no clímax da narrativa, como faz:

Simone - G4/O - berrei tanto, tanto naquela frente daquele sobrado, nunca fiquei com tanto medo na minha vida, parecia que eu ia morrer ali eletrocutada como disse uma amiga minha, aí eu chorei, chorei, chorei ali fora, bati, bati na porta, aí abre a porta, meu pai... minha mãe, aí fiquei feliz, tava quentinha em casa, protegida.

G/E - (...) Cheguei em casa e não vi ninguém tudo estava fechado, entrei em pânico total mas meu pai abre a porta. Nunca dei tanto valor a um lar.

O achado no escrito, aparentemente, contraria a conclusão de Wolfson (1979), que considera a alternância P/PH como traço exclusivo das narrativas orais performativas, assim denominadas porque compartilham semelhanças com uma 36 
apresentação teatralizada: diálogos, gestos, apartes, repetições, sons expressivos e efeitos sonoros. Da mesma forma, essa afirmação pode ser contestada pelos achados nas nossas HQs que em nenhum momento foram dramatizadas, mas também apresentam troca $\mathrm{P} / \mathrm{PH}$.

Nossos achados de P/PH ocorreram também em sequiências seguidas, de forma diversa dos exemplos até aqui apresentados:

Tatiana - G4/E - Uma menina estava pintando (desenhando) um menino, numa parede de uma casa, então a dona da casa abre a porta e fica brava. A menina pega então um sabão e apaga o menino, então ela (menina) não entendendo o que a dona queria, refez o menino só que agora agradecendo.

Essas seqüências seguidas parecem estar correlacionadas com o uso do conetivo $e$. Pode-se supor uma correlação entre parataxe e troca de tempo verbal de forma semelhante à proposição de Fleischman (1985). Essa autora, após analisar textos medievais franceses, aponta que a variação de tempo tende a ocorrer quando orações sucessivas estão meramente justapostas sem nenhum conetivo explícito a ligá-las. Sempre que houver uma conjunção causal, o tempo é mantido. Nossos dados mostraram uma correlação parecida: há alternância para $\mathrm{PH}$ na seqüência de orações sem nenhum conetivo explícito. Ocorre volta ao uso do passado, quando acontece a explicitação de uma conjunção. $\mathrm{O}$ exemplo de Tatiana mostra bem claramente o que se argumenta: à seqüência de quatro orações no presente, seguese uma oração no passado, introduzida pelo conetivo então. Por sua vez, o uso do presente vincula-se à função de separar o background do início do foreground da narrativa.

É importante assinalar que a troca Pretérito/PH sempre representa uma interrupção no que vinha sendo apresentado: ou para apontar a passagem do background para o foreground, ou na própria linha temática da narrativa (caso da ocorrência em clímax ou numa relação adversativa). Esses resultados, embora não sejam exatamente os mesmos, vão na direção dos achados de Schiffrin (1981) e Silva-Corvalán (1983), na análise de narrativas conversacionais, quando sugeriram que a mudança para PH marca limites de evento (independentemente de sua conceituação problemática do que seja um evento). Fleischman (1985), por outro lado, nota que, nas narrativas medievais analisadas, uma interrupção na linha principal do evento da narrativa representa necessariamente uma transição: seguidamente para uma troca de tópico, ou para a fala de um participante para outro e que esse movimento é geralmente precedido pela inserção de alguma informação de background.

Como conclusão do estudo das funções de PH no Contexto das narrativas infantis, pode-se afirmar que seu uso na narrativa oral não deve ser visto como um simples artifício estilístico para substituir o passado, tal como preconiza a gramática tradicional. Esse é o motivo pelo qual não se pode aceitar que a função geral apresentada para PH cubra as funções particulares que acontecem dentro do contexto discursivo. Como mostraram nossos exemplos, a alterância passado/ $\mathrm{PH}$ deve ser entendida como um dos recursos gramaticais disponíveis ao falante na 
narrativa de eventos, com que pode marcar as passagens que quer tornar mais salientes, mais próximas do ouvinte, ou com que pode assinalar a segmentação dos eventos de seu texto. Outra conclusão a inferir do estudo é a de que o significado de $\mathrm{PH}$ só pode ocorrer ligado ao contexto em que ocorre.

A maior parte das ocorrências de alternância com presente ocorreu no background das narrativas, muito associado ao que Labov (1972) chama de orientação, ou seja, no momento em que o falante contextualiza sua narrativa em relação ao ambiente, tempo, personagens, enfim provê o ouvinte das condições necessárias para o entendimento do foreground.

Habitualmente, nesta parte da história, espera-se o uso do imperfeito, como sugerem Hopper e Thompson (1980):

Eduardo - G2/O - eu e meu irmão estávamos surfando lá na praia quando... e a gente era um pouco pequeno e a gente tava usando pranchas de isopor...

- G2/E - Eu e meu irmão estávamos surfando com pranchas de isopor, quando erámos menores.

Gislaine - G2/O - tá, era uma vez, uma menina que ela não tinha nada pra fazer...

- G2/E - Era uma vez uma menina que não tinha nada para fazer.

Nossos dados mostraram que também o presente é usado nessas circunstâncias. Não se pode afirmar, entretanto, que se caracteriza um uso de PH nesses casos, uma vez que não há indicações de que refira a situações passadas. Trata-se, pois, de um uso do presente, com seu valor habitual, ligado ao tempo da fala. Um desses usos está relacionado à descrição do personagem da narrativa, quando os traços descritos são independentes dos demais eventos descritos:

Tobias - G2/O - assim, tem uma velha tri chata o nome dela é Julieta ela: ela mora do lado da minha casa (o meu ir, daí o meu irmão um dia) ah! ela vive jogando praga pro meu irmão né até que um dia...

- G2/E - Eu tenho uma vizinha tri chata que ela jogava praga para o meu irmão...

Note-se que o informante, no escrito, começa com o presente, mudando em seguida, ou seja, ainda dentro da orientação, para o imperfeito. O presente está ligado à apresentação da personagem e sua principal caracterização (tri chata), já o imperfeito relaciona uma ação habitualmente praticada pela personagem.

Em toda as ocorrências de presente na orientação, a troca para o pretérito assinala uma diferente seção da narrativa, normalmente associada ao seu foreground ou ao que Labov denomina de ação complicadora. A troca de volta ao presente pode ser relacionada a um retorno à orientação, como mostra o exemplo de:

Lilian - G2/E - Foi quando eu e minha turma fomos no Jardim Botânico. Quando a gente saiu do ônibus todos pisamos na grama, e recebemos um bilhetinho porque os guardas nos ajudam, etc...

A segunda oração assinala o início do foreground da história, a última oração encaixada (indevidamente por um conetivo causal) dá a informação contida 
no bilhetinho (o background). Para ela, a informante reserva uma ocorrência de presente, que assinala a volta ao contexto de orientação.

A troca para o presente assinalou também a parte final do texto, como sua resolução, que constituiu, nos casos de ocorrência de presente, também uma coda ou uma volta ao momento da enunciação.

Tatiana - G4/O - (...) então pedi para Juliana, uma amiga minha, o qué que a galinha come e ela me disse milho, acontece que eu entendi pinho eu escrevi né, pinho na prova, então até hoje, meu irmão goza comigo por causa disso.

- G4/O - (...) e ela me disse milho, mas eu entendi pinho, mas o verdadeiro problema é que até hoje o meu irmão, o Diogo goza de mim por causa disso.

A primeira alternância com presente no oral (e essa não foi passada para o escrito) representa a relação adversativa que motiva toda a ação complicadora (assinalada pelo conector mas no escrito). A segunda alternância, que permanece no escrito, traz de volta o momento da enunciação (até hoje).

Houve também ocorrência de presente nos comentários, que servem como uma espécie de avaliação da narração, em que o falante busca recursos para continuar sua narrativa, num jogo retórico bastante freqüente na conversação, em que a interrupção é aparentemente destinada a captar a atenção do ouvinte:

Alexandre - G1/O - a gente tava andando aí num lugar não me lembro onde né, e aí uh, e aí o pai vinha vindo tinha um carro estacionado né, aí meu pai bateu e, ãh, como que é? a minha irmã, e a minha irmã: como que é? deixa eu me lembrar, a minha irmã: deixa eu ver a minha irmã bateu com a testa, o resto eu não lembro mais.

Como a análise bem mostrou, o uso de presente no contexto das narrativas teve sempre uma função pragmática, tanto no foreground, quanto no background. Verificando a sequiência temporalmente ordenada, ou seja, o foreground das narrativas, observa-se que todas as ocorrências de presente podem ser substituídas por pretérito perfeito sem que se altere a relação aspectual que ali se instaura (seria impossível substituí-lo por imperfeito, por exemplo). Ou seja, como o pretérito perfeito, no contexto do foreground narrativo, $\mathrm{PH}$ é usado para codificar eventos passados, punctuais, temporalmente ordenados. Dentro do foreground de uma narrativa, contudo, esses dois tempos, contextualmente equivalentes sob o ponto de vista tempo/aspecto, parecem contrastar num eixo de saliência, como afirma Fleischman (1985). Os eventos codificados por PH no foreground correspondem aos mais salientes, como destacamos nos exemplos de acontecimentos em clímax ou de relação adversativa.

Por outro lado, a ocorrência de presente no contexto de background, como orientação da narrativa, é equivalente ao uso do imperfeito, apresentando, então, aspecto imperfectivo. (Mesmo nos contextos em que não há correspondência com o imperfeito, como nos comentários, o aspecto é imperfectivo.) Nesse caso, não parece que os eventos codificados por presente possam ser considerados eventos anteriores ao tempo da narrativa. Na verdade, eles marcam sempre uma 
segmentação dos eventos narrados, pois cortam o fluxo narrativo, seja para dar uma orientação, para fazer um comentário ou para finalizar o que estava sendo contado, constituindo, pois, uma volta ao momento da enunciação, ou seja, ao tempo da fala.

Foi possível, pois, distinguir dois usos do presente, que alternam com o passado:

- um, que ocorre no foreground narrativo, com clara referência à situação passada, com aspecto perfectivo e que pode ser entendido como Presente Histórico;

- outro, que ocorre no background narrativo, sem referência a tempo passado, geralmente com aspecto imperfectivo e que deve ser entendido com o valor temporal de presente. Observou-se ainda o uso do presente nas citações. O resultado do corpus mostrou que o uso mais freqüente de presente nas citações está relacionado com o discurso direto, tendendo a ocorrer mais no oral.

Na comparação entre as faixas etárias analisadas, não há diferença com relação ao uso de presente no oral; como demonstram os trabalhos sobre narrativas conversacionais, este também é um traço da linguagem dos adultos. Em termos de escrito, porém, o mesmo não acontece. Os grupos mais velhos mostraram uma tendência a usar menos alternância presente/passado, deixando-as reservadas para os momentos mais tradicionalmente aceitos: clímax, resolução/coda, citações, os quais até diríamos estilisticamente marcados. Em nenhum dos grupos, levando-se em consideração as condições pragmáticas que justificam a alternância de tempo verbal, pôde-se verificar ruptura de coesão textual. Tal fato pode levar à conclusão de que as crianças das faixas etárias descritas reconhecem a função das oposições tempo/aspecto na produção de seus textos orais e escritos e delas se valem de forma a manter a coesão desses textos.

\section{BIBLIOGRAFIA}

BEAUGRANDE, R. Text linguistics through the years. Text, v.10, n.1-2, p.9-17, 1990.

FLEISCHMANN, S. Discourse functions of tense-aspect oppositions in narrative: toward a theory of grounding. Linguistics, v.23, p.851-82, 1985.

GUIMARÃES, A. M. M. O desenvolvimento de coesão: estratégias da passagem do contexto ao texto. PUCRS, 1990. (tese de Doutorado).

HOPPER, P. Aspect and foregrounding in discourse. In: GIVÓN, T. Discourse and syntax. New York, Academic Press, 1979. v.12.

HOPPER, P. S.; THOMPSON, S. A. Transitivity in grammar and discourse. Language, v.56, p.251-99, 1980.

LABOV, W.; WALETZLEY, S. Narrative analysis: oral versions of personal experiences. In: HELM, J. (ed.). Essays on the verbal and visual arts. Seattle, University of Washington, 1967. 
LABOV, W. Sociolinguistic patterns. Philadelphia, University of Pennsylvania, 1972.

MIRA MATEUS, M. H. et alii. Gramática da língua portuguesa. Coimbra, Almedina, 1983.

REICHEMBACH, H. Elements of symbolic logic. New York, The Fine Press, 1947.

REINHART, T. Principles of gestalt perception in the temporal organization in narrative texts. Linguistics, v.22, p.779-809, 1984.

ROMAINE, S. The language of children and adolescents: the acquisition of communicative competence. Oxford, Basil Blackwell, 1984.

SCHIFFRIN, D. Tense variation in narrative. Language, v.57, p.45-62, 1981.

WOLFSON, N. B. The conversational historical present in American English narrative. University of Pennsylvania, 1976. (tese de Doutorado).

WOLFSON, N. B. The conversational historical present alternation. Languages, v.55, p.168-82, 1979. 
